\title{
Equity And Diversity In Tertiary Institutions
}

Greg Tower, Curtin University of Technology, Australia Julie Plummer, University of Western Australia, Australia

Brenda Ridgewell, Curtin University of Technology, Australia

Emily Goforth, Curtin University of Technology, Australia

Spence Tower, Ferris State University, USA

\begin{abstract}
The results reveal that tertiary institutions have low levels of EEO reporting especially for sexual orientation and religious issues. More mandatory state-based legislation may be needed.
\end{abstract}

\section{SECTION 1 INTRODUCTION AND LITERATURE REVIEW}

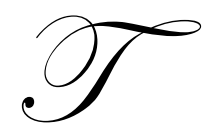

he higher education sector represents a substantive part of the Australian economy, especially in regards to international trade. Norton (2008) notes that education is now Australia's biggest services export, overtaking tourism by nearly $\$ 1$ billion for 2007 ( $\$ 12.5$ billion versus $\$ 11.5$ billion)

(http://andrewnorton.info/blog/2008/02/06/is-education-really-australias-biggest-services-export/). As large employers, higher education institutions have major equal employment and opportunity (EEO) issues to deal with. This paper explores key EEO-style equity and diversity policies and procedures for all Australian tertiary institutions. This study is conducted in the positivist school of research with an empirical quantitative research design. It seeks to explain the level of communication and activity regarding EEO issues in a broad context. This study first provides a review of the relevant EEO literature and then relates these themes to Australian university activities. Special emphasis is placed on university policies on sexual orientation, gender, religion, race and treatment of disabilities.

\section{Various aspects of equal employment opportunity human capital studies}

Among the aspects examined in the corporate social reporting (CSR) research is on human resource or human capital disclosure aspect. Vuontisjarvi (2006) applies content analysis techniques to explore the nature of human resource for the 205 biggest Finnish companies' annual reports. The human resource information is classified into 10 themes namely: training and staff development; pays and benefits; participation and staff involvement; values and principles; employee health and well-being; measurement of policies; employment policy; security in employment; equal opportunities and work-life balance. The themes are further categorized into three indicators, that is, principles, and process and performance indicators. The focus of disclosures was on theme 'training and staff development', 'pay and benefits' and 'staff involvement'. The authors found that the disclosures are mostly qualitative in nature. The highest score for performance indicators fell under the theme' equal opportunities' and provided numerical evidence about personnel structure such as 'breakdown by age', 'average age', and 'breakdown by full-time or part-time contracts'. As a whole, the findings indicate that the disclosures are disproportionate and disparate making comparison of results very difficult. Themes such as equal opportunity and work life balance are generally ignored.

Day and Woodward (2004) examined the employee reporting practices of FTSE 100 companies in the annual report for the year 2000. Again, the content analysis method is used to measure the disclosure level of employee reporting. The findings reveal that many companies do not disclose the four mandated areas required by the Companies Act statutory requirement. These findings imply that certain user needs are not currently being met. About half of the companies promote awareness of financial and economic factors affecting performance. The study concluded that even though there are disclosures present, they often appear to lack conviction, adhering only to some type of minimum compliance regime. 
Abeysekera and Guthrie (2004) examine disclosure patterns of human capital reporting in Sri Lanka to determine differences in disclosure patterns between Sri Lanka and developed nations. Content analysis was performed on the annual reports of the top 30 listed companies in the CSE based on the market capitalization for 1998/1999 and 1999/2000. Each item was recorded by line count and by frequency of occurrence under human capital category. In the period under study, it was discovered that Sri Lanka companies mostly disclose employee contribution information. Equity issues are one of the least reported items in the Sri Lanka companies' annual reports with only one company communicating this information. One possible reason for this non-disclosure is that reporting more information about lack of employment opportunities for disabled people could lead to more tension between firms and the government. In comparison to Guthrie and Perry (2000) the most reported attribute is entrepreneurial spirit. Abeysekera and Guthrie (2004) concluded that the differences in human capital reporting in both countries are factors such as political, social and economic institutional framework.

The inherent motivations for human capital disclosure in annual reports are examined by Abeysekera (2008). The content analysis method is used to ascertain the human capital disclosure in annual reports in 2001 and 2002, with semi-structured interviews conducted to further understand the reasons for disclosure. The top 30 companies in Sri Lanka by market capitalization are chosen as the samples for this research. The selected interviewees are holding senior positions in the organizations chosen based on stratified sampling technique. The human capital items in this study are grouped into seven categories: employee relations, employee measurement, training and development, entrepreneurial skills, employee welfare, equity issues and workplace safety. Abeysekera (2008) noted that the most disclosure on employee relations which includes thanking employees for contributions and reporting about the good relations with their workers union. The key insights for such disclosures revealed by the interviewees are: 1) restructuring of firm's activities; 2) steering towards knowledge-based economy and 3) having relationship with capital provider will increase capital accumulation. Further analysis revealed that the least disclosed items are on workplace safety and equity issues. Interviews reveal factors for such a low level of communication. These were poor infrastructure for disabled, no insurance coverage for disabled workers, factors such as working hours and nature of business which restrict the employment of women, and economic factors. The study concludes that the characteristics of the social constituency also may influence the human resource reporting practices in Sri Lanka.

Brown et al (2005) explore the disclosure of human resource information in 110 companies' annual reports of the Pacific Island countries (PIC). A human resource disclosure index (HRDI) is developed to quantify the disclosure of human resource information. In relation to this, four hypotheses were developed which examine the extent of human resource disclosure with four independent variables i.e. type of ethic culture background, type of industry, type of entity and political visibility of an entity. The multiple regression found no significant association between the extent of human resource disclosure with all the variables; there was uniformity of reporting across different types of entities. In stage two of the study, a questionnaire was administered to compare and contrast PIC user and preparer needs of human resource disclosure. The results show that there is no significant difference between users' and preparers' rating of the importance of eight categories of human resource disclosure.

A highly regarded corporate equal opportunity disclosure article is by Adam et al. (1995). Their article examines corporate accountability for equal opportunity issues which involve samples of top 100 UK companies listed in The Times 1,000 for the year ended 1991. The content analysis instrument is developed to analyse the equal opportunities information categorized into: 1) specific equal opportunities policy; 2) other evidence of equal opportunities commitment and 3) reference to external pressure, initiatives and legislation. Sub-categories include the 'minority' group; type of information (financial, quantitative or discursive); the location of information in the corporate annual report. The length of equal opportunity disclosure is measured based on the proportion of the page. Overall, they found out that the mandatory and voluntary disclosure level for EEO information is very low. The most reported item of information is on application and recruitment in regards to equal opportunity. The majority of information disclosure is placed in Directors' Report section. This seems to be mainly due to the fact that there is statutory requirement for disclosing information regarding disabled employees. In general, there is minimum disclosure on monitoring and working conditions, age, and religion. Adam et al. (1995) concluded that there is noncompliance of disabled people policies and there is large-scale non-disclosure on equal opportunity information. They state the reasons for such non-disclosure may be due to political and economic factors. 
Further in 2000, Adam and Harte review EEO reporting literature and develop proposals for improvement. They consider the discrimination incidence in employment using the accounting profession as a case study and explore accounting to reveal discrimination practices. In doing so, they focus on the position of woman, ethic minorities and disabled people in employment in Britain. They highlight that women are disadvantaged in employment aspects such as pension entitlements, benefits payment and training opportunities. In relation to ethnic minorities, Adam and Harte (2000) speak about the ethnic minorities' existence in 1990s in Britain, with significant difference in the economic activity rates of the various ethnic groups, particularly woman. Meanwhile, they observe that only one third of the total disabled people population are employed. The authors posit that "the absence of reporting on employment is particularly significant in societies such as Britain, which prefer voluntaristic rather than regulatory approaches in the administration of affairs:" (p.60). Adam and Harte (2000) note that in Britain only one statutory requirement exists for disabled people disclosure; this is stipulated in the Companies Act 1985 . The authors question the premise of a successful voluntary disclosure system for EEO reporting due to factors such as: 1) the tendency of extant equal opportunity reporting to not be reflective of performance but rather may currently be a covert attempt to mislead; 2) need to have internal monitoring systems; and 3) the development of worthwhile initiatives such as standards. The authors conclude the paper with a number of specific proposals for improvement of corporate policies: monitoring and targets, formal investigation, case law and involvement of workers and statutory authorities to address how equal opportunity reporting may be best developed.

Duff and Ferguson (2007) examine the UK accounting profession's response to changes in disability legislation. They derive two sources of evidence to assess accounting firm's attitude to disability namely survey and content analysis of the 2003 annual reviews of Big Four accounting firms. The questionnaires were distributed by using stratified sampling technique to: the top $50 \mathrm{UK}$ accounting firms and 500 firms outside the Top 50 firms randomly selected from the 2003 ICAEW directory of firms. The findings from their survey reveal :"(i) all respondents had an equal opportunity policy sometimes very general and unwritten, but disabled people are not specifically addressed in most policies; (ii) firms generally do not participate in voluntary initiatives schemes, with only two accounting firms beings members of Employees Forum of Disability (EFD), similarly none had adopted 'two-ticks'; (iii) a relatively low proportion of disabled people are employed by UK accounting firms; and (iv) a lack of recruitment employment processes, including insufficient monitoring of applications from disabled people, limited procedures to encourage staff and partners to self-identify themselves as disabled, and few positive actions to recruit disabled people" (pp.149-150). Analysis from the annual reviews reveals that the firms regarded their employees as 'good'. Each firm provides some evidence of its commitment to diversity within its annual review documents. Yet, Duff and Ferguson (2007) found that none of the four annual review documents provided any images of visibly disabled people either as employee, client or as beneficiaries of the firms or related involvement in community initiatives. The authors thus conclude that UK firms have made few visible attempts to comply with legislation or address the exclusion of disabled people.

Grosser and Moon (2006) examine best practice reporting on gender equality in the UK. Their study investigates improvements in reporting on gender equality in the workplace by twenty UK best practice companies. Their study employs mixed methods: (a) quantitative analysis of gender impact reporting by companies; and (b) qualitative analysis by interviewing the company representatives of the drivers for reporting and reasons for nondisclosure of information. Grosser and Moon (2006) observe that the reporting of gender, impact and performance is still generally low in spite of the widespread reporting of broader gender diversity policies and programs. They also noted a considerable amount of non-disclosure information internally generated for other purposes. Their interview findings indicate that the disclosure decisions are influenced by market, civil society and governmental, along with firm-specific organizational factors, poor performance and anxieties about the misuse of data. The perceptions on lack of demand for more detailed impact reporting and risks arising from negative media climate also contribute to the factor of the companies' reluctance to disclose more gender information.

Adams and McPhail (2004) carry out a longitudinal study on non-disclosure with respect to a specific type of social reporting-the employment of ethnic minorities. Such a focus allows for a detailed analysis of the social, political and economic content of (non) disclosure. Their examination is based on an empirical analysis on ethnic minorities made by large companies in the retail and banking sectors during the period $1935-1998$. The authors argue that studying the social and political context in which disclosure were made can assist in understanding the disclosure or non-disclosure of ethnic minorities. Archival research is used to gather data in relation with social, 
political and economic environment. Content analysis is used to analyse the data into three time periods. The key findings are that:

- The period from 1935 to 1975 failed to highlight any disclosure on ethnic minorities in both sectors.

- $\quad$ The period from 1976 to 1990 shows the inception of race disclosure in the annual reports and generally in a form of equal opportunity policy statements.

- Whereas, the period from 1991 to 1998 shows a significant increase in ethnic minorities' disclosures.

Adams and McPhail (2004) argue that many companies report on equal opportunities but only in bland overview statements with few disclosing information other than generic policy statements. Adams and McPhail (2004) concluded that the changes in the disclosure pattern are influenced by change of social, politic and economic environment. They also highlight the incompleteness of corporate social reporting theories with regard to nondisclosure explanation.

In aggregate, the above literature notes the importance of looking at higher education institutions with their large employee base and influence on the community they clearly have major equal employment and opportunity (EEO) issues to deal with. This paper thus explores key EEO policies and procedures for all Australian universities with special emphasis placed on policies on sexual orientation, gender, religion, race and treatment of disabilities. Day and Woodward (2004) note that entities communication of such issues often appear cursory and adhere only to a minimum compliance regime. Adam et al. (1995) observe that mandatory and voluntary disclosure level for EEO information is very low with minimum disclosure on monitoring and working conditions, age, and religion. Adams and McPhail (2004) argue that many companies report on equal opportunities but only in bland overview statements with few disclosing information other than generic policy statements.

These above studies point to the dearth of information of EEO policies. This study thus seeks to provide more data on a major Australia sector of the economy, the higher education universities. The analysis will be conducted both on an aggregate EEO basis as well as on the five key sub-categories as documented in the following section.

\section{SECTION 2 EEO DATA FINDINGS}

The entire population of the 38 Australian universities are analysed to examine their EEO activities and communication. The main information source utilized is the most recent (2006 fiscal year end) annual report.

The main dependent variable utilized is an Equal Employment and Opportunity Disclosure Index (EEODI) composed of 104 information points in total. This is calculated from a base of 20-23 key issues on policies and programs for each of the following major categories: 1) sexual orientation; 2) gender; 3) religion; 4) race and 5) disabilities.

Figure 1 reveals the overall level of EEO disclosure is $29.14 \%$. The figure also highlights major differences in these categories with communication patterns ranging from less than $9 \%$ disclosures for sexual orientation issues to a high of approximately $40 \%$ for race items. Lack of transparency is thus a major concern with low levels of reporting for all these key EEO categories. 
Figure 1: Australian Tertiary Institutions' EEO Disclosure Levels

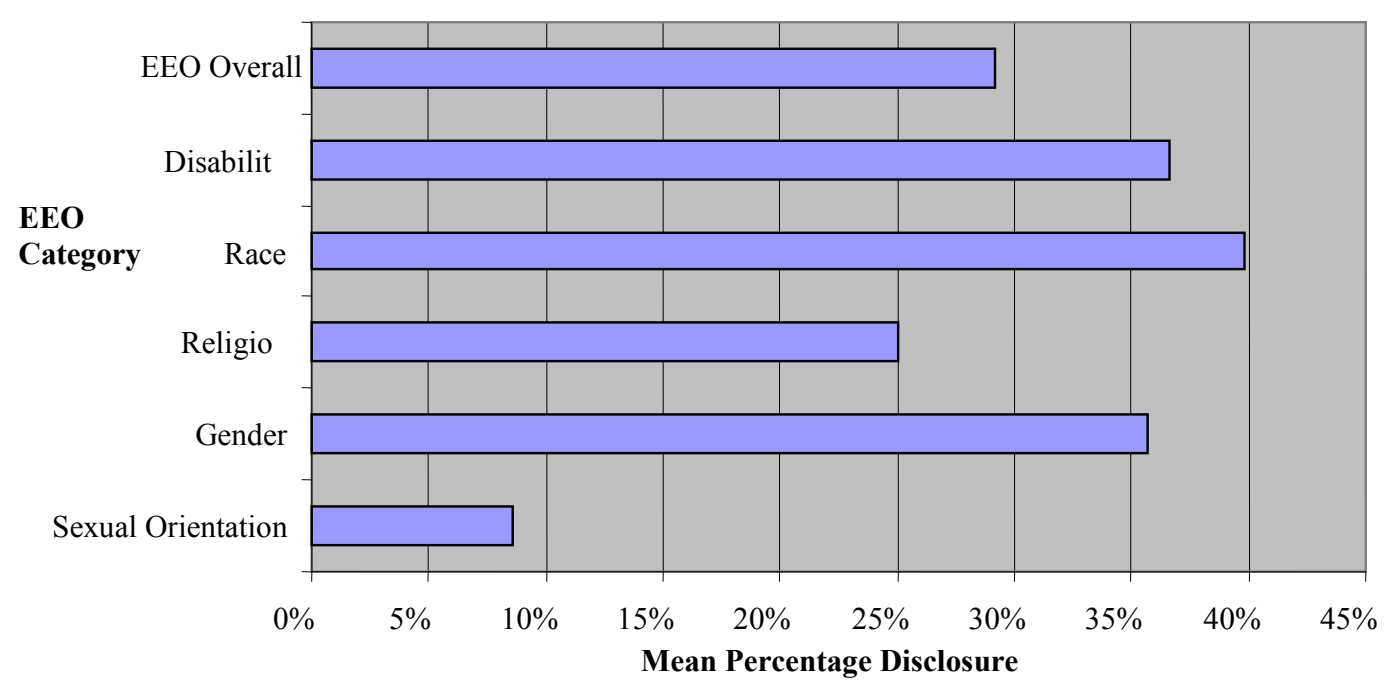

Table 1 presents these categories and the percentage of Australian universities that have clear disclosure activities on each item.

Table 1: Detailed Analysis of EEO Items for Australian Tertiary Institutions

\begin{tabular}{|l|c|}
\hline Sexual Orientation (Mean Average 8.55\%) & \\
\hline $\begin{array}{l}\text { Have developed and implemented: a code of practice to deal with prejudice, discrimination harassment } \\
\text { endured by staff and students }\end{array}$ & $23.68 \%$ \\
\hline Have developed and implemented: policies for fair employment and promotion procedures & $18.42 \%$ \\
\hline Have developed and implemented: anti-discrimination programs & $18.42 \%$ \\
\hline Have developed and implemented: fair grading and enrolment procedures & $15.79 \%$ \\
\hline Have developed and implemented: sexual orientation in the university policy statement & $10.53 \%$ \\
\hline provide the following services: crisis counseling & $7.89 \%$ \\
\hline provide the following services: peer support groups & $7.89 \%$ \\
\hline provide the following services: guidance services & $7.89 \%$ \\
\hline policies for dealing with social ostracism & $7.89 \%$ \\
\hline policies for dealing with diminished self-esteem & $7.89 \%$ \\
\hline policies for dealing with bullying & $7.89 \%$ \\
\hline provide the following services: social education & $5.26 \%$ \\
\hline provide the following services: health education & $5.26 \%$ \\
\hline policies for dealing with fear & $5.26 \%$ \\
\hline provide the following services: transgender education & $2.63 \%$ \\
\hline provide the following services: legal rights education & $2.63 \%$ \\
\hline $\begin{array}{l}\text { Have developed and implemented: policies which guarantee that faculty and students will be able to pursue } \\
\text { research interests on homosexual topics without jeopardizing their academic or professional well being }\end{array}$ & $2.63 \%$ \\
\hline Have developed and implemented: policies for dealing with infectious diseases (for example HIV) & $2.63 \%$ \\
\hline provide the following services: legal clinic & $0.00 \%$ \\
\hline policies for dealing with suicide attempts & $0.00 \%$ \\
\hline
\end{tabular}




\begin{tabular}{|l|c|}
\hline Gender (Mean Average 35.70\%) & $78.95 \%$ \\
\hline Have developed and implemented: incentives for females to study non-traditional fields & $71.05 \%$ \\
\hline $\begin{array}{l}\text { Have developed and implemented: a code of practice to deal with prejudice, discrimination harassment } \\
\text { endured by staff and students }\end{array}$ & $68.42 \%$ \\
\hline Have developed and implemented: policies for fair employment and promotion procedures & $63.16 \%$ \\
\hline Have developed and implemented: policies for fair grading and enrolment procedures & $57.89 \%$ \\
\hline Have developed and implemented: anti-discrimination programs & $50.00 \%$ \\
\hline provide the following services: guidance services & $50.00 \%$ \\
\hline Have developed and implemented: policies which deal with pregnancy in staff population & $47.37 \%$ \\
\hline provide the following services: social education & $44.74 \%$ \\
\hline Have developed and implemented: policies which ensure fair treatment of pregnant students & $39.47 \%$ \\
\hline provide the following services: peer support groups & $31.58 \%$ \\
\hline provide the following services: legal rights education & $26.32 \%$ \\
\hline provide the following services: crisis counseling & $26.32 \%$ \\
\hline Have developed and implemented: gender orientation in the university policy statement & $26.32 \%$ \\
\hline $\begin{array}{l}\text { Have developed and implemented: policies which guarantee that faculty and students will be able to pursue } \\
\text { research interests on gender specific topics without jeopardizing their academic or professional will being }\end{array}$ & $23.68 \%$ \\
\hline policies for dealing with bullying & $23.68 \%$ \\
\hline policies for dealing with social ostracism & $21.05 \%$ \\
\hline policies for dealing with diminished self-esteem & $21.05 \%$ \\
\hline provide the following services: health education & $13.16 \%$ \\
\hline policies for dealing with fear & $7.89 \%$ \\
\hline Have developed and implemented: incentives for males to study non-traditional fields & $5.26 \%$ \\
\hline provide the following services: transgender education & $2.63 \%$ \\
\hline policies for dealing with suicide attempts & $2.63 \%$ \\
\hline provide the following services: legal clinic & \\
\hline
\end{tabular}

\begin{tabular}{|l|c|}
\hline Religion (Mean Average 25.00\%) & $39.47 \%$ \\
\hline Have developed and implemented: anti-discrimination programs & $39.47 \%$ \\
\hline $\begin{array}{l}\text { Have developed and implemented: a code of practice to deal with prejudice, discrimination harassment } \\
\text { endured by staff and students }\end{array}$ & $39.47 \%$ \\
\hline Have developed and implemented: policies which deal with diversity of religion in the staff population & $39.47 \%$ \\
\hline Have developed and implemented: policies which deal with diversity of religion in the student population & $34.21 \%$ \\
\hline Have developed and implemented: policies for fair employment and promotion procedures & $34.21 \%$ \\
\hline Have developed and implemented: policies for fair grading and enrolment procedures & $31.58 \%$ \\
\hline provide the following services: guidance services & $26.32 \%$ \\
\hline provide the following services: peer support groups & $26.32 \%$ \\
\hline provide the following services: social education & $23.68 \%$ \\
\hline provide the following services: crisis counseling & $23.68 \%$ \\
\hline provide the following services: legal rights education & $23.68 \%$ \\
\hline Have developed and implemented: religious policies in the university statement & $21.05 \%$ \\
\hline policies for dealing with bullying & $21.05 \%$ \\
\hline policies for dealing with social ostracism & $15.79 \%$ \\
\hline policies for dealing with diminished self-esteem & $15.79 \%$ \\
\hline policies for dealing with fear & $13.16 \%$ \\
\hline provide the following services: facilities for students/staff to worship in accordance with their specific religion & $10.53 \%$ \\
\hline provide the following services: health education & $7.89 \%$ \\
\hline policies for dealing with suicide attempts & $7.89 \%$ \\
\hline $\begin{array}{l}\text { Have developed and implemented: policies which guarantee that faculty and students will be able to pursue } \\
\text { research interests on religiously specific topics without jeopardizing their academic or professional well being }\end{array}$ & $5.26 \%$ \\
\hline provide the following services: legal clinic & \\
\hline
\end{tabular}




\begin{tabular}{|l|c|}
\hline Race (Mean Average 39.87\%) & \\
\hline $\begin{array}{l}\text { Have developed and implemented: a code of practice to deal with prejudice, discrimination harassment } \\
\text { endured by staff and students }\end{array}$ & $71.05 \%$ \\
\hline Have developed and implemented: policies which deal with diversity of race in the staff population & $68.42 \%$ \\
\hline Have developed and implemented: policies which deal with diversity of race in the student population & $68.42 \%$ \\
\hline Have developed and implemented: policies for fair grading and enrolment procedures & $65.79 \%$ \\
\hline Have developed and implemented: policies for fair employment and promotion procedures & $60.53 \%$ \\
\hline Have developed and implemented: anti-discrimination programs & $57.89 \%$ \\
\hline provide the following services: peer support groups & $52.63 \%$ \\
\hline provide the following services: social education & $52.63 \%$ \\
\hline provide the following services: guidance services & $47.37 \%$ \\
\hline provide the following services: crisis counseling & $42.11 \%$ \\
\hline Have developed and implemented: racial policies in the university statement & $36.84 \%$ \\
\hline policies for dealing with social ostracism & $28.95 \%$ \\
\hline provide the following services: legal rights education & $28.95 \%$ \\
\hline policies for dealing with bullying & $26.32 \%$ \\
\hline policies for dealing with diminished self-esteem & $18.42 \%$ \\
\hline policies for dealing with fear & $18.42 \%$ \\
\hline provide the following services: health education & $18.42 \%$ \\
\hline $\begin{array}{l}\text { Have developed and implemented: policies which guarantee that faculty and students will be able to pursue } \\
\text { research interests on racially specific topics without jeopardizing their academic or professional well being }\end{array}$ & $15.79 \%$ \\
\hline provide the following services: legal clinic & $10.53 \%$ \\
\hline policies for dealing with suicide attempts & $0.00 \%$ \\
\hline
\end{tabular}

\begin{tabular}{|l|c|}
\hline Disability (Mean Average 36.58\%) & \\
\hline $\begin{array}{l}\text { Have developed and implemented: policies which deal with problems faced because of the disability in the } \\
\text { staff population }\end{array}$ & $71.05 \%$ \\
\hline Have developed and implemented: policies for fair employment and promotion procedures & $71.05 \%$ \\
\hline Have developed and implemented: policies for fair grading and enrolment procedures & $68.42 \%$ \\
\hline $\begin{array}{l}\text { Have developed and implemented: policies which deal with the problems faced because of the disability in the } \\
\text { student population }\end{array}$ & $63.16 \%$ \\
\hline $\begin{array}{l}\text { Have developed and implemented: a code of practice to deal with prejudice, discrimination harassment } \\
\text { endured by staff and students }\end{array}$ & $36.84 \%$ \\
\hline Have developed and implemented: anti-discrimination programs & $36.84 \%$ \\
\hline Have developed and implemented: disability policies in the university statement & $34.21 \%$ \\
\hline policies for dealing with bullying & $34.21 \%$ \\
\hline policies for dealing with social ostracism & $31.58 \%$ \\
\hline policies for dealing with diminished self-esteem & $31.58 \%$ \\
\hline provide the following services: peer support groups & $28.95 \%$ \\
\hline policies for dealing with fear & $26.32 \%$ \\
\hline provide the following services: guidance services & $26.32 \%$ \\
\hline provide the following services: social education & $21.05 \%$ \\
\hline provide the following services: crisis counseling & $18.42 \%$ \\
\hline policies for dealing with suicide attempts & $18.42 \%$ \\
\hline provide the following services: legal clinic & $13.16 \%$ \\
\hline provide the following services: health education & $13.16 \%$ \\
\hline provide the following services: legal rights education & $0.00 \%$ \\
\hline $\begin{array}{l}\text { Have developed and implemented: policies which guarantee that faculty and students will be able to pursue } \\
\text { research interests on disability specific topics without jeopardizing their academic or professional well being }\end{array}$ & \\
\hline
\end{tabular}


Table 1 reveals differing levels of EEO data by Australian universities. It provides a wealth of detail for EEO, classified into five major categories, over 104 specific items. The key trends are:

- $\quad$ The 'Sexual Orientation' category had the lowest level of reporting (8.55\%) and also had the lowest standard deviation (19.96\%). There was little reported and little variance in this reporting. Only a code of practice to deal with prejudice, discrimination harassment endured by staff and students was disclosed by more than $20 \%$ of the Australian universities. No institution communicated data on legal remedies or suicide attempts and surprisingly only one university disclosed information on the key issue of dealing with infectious diseases (for example HIV).

- 'Gender' disclosures ranged in the middle (35.70\%). Over two thirds of the universities discussed the ability for females to study non-traditional fields, a code of practice to deal with prejudice, discrimination and harassment endured by staff and students, and policies for fair employment and promotion procedures.

- $\quad$ 'Religion' issues communication patterns were second lowest (mean $25.00 \%$, std dev of $34.97 \%$ ) No issue had over $40 \%$ reporting not even religious-based anti-discrimination programs or a code of practice to deal with prejudice, discrimination harassment endured by staff and students. Legal remedies had the lowest level of data.

- $\quad$ Appropriately, in a country that treasures its multicultural heritage the level of 'Race' disclosures were the highest (mean 39.87\%). Eight broadly ranging items were disclosed by over $50 \%$ of the Australian universities.

- $\quad$ The 'Disability' category had the second highest reporting trend (36.58\%). Many key disability policies were disclosed by over $60 \%$ of the tertiary institutions but actual university services on guidance counseling, social education and crisis counseling bullying were only communicated by approximately one fourth of the Australian universities. .

The Figure 1 and Table 1 data reveal a wide range of EEO reporting patterns. Overall, the university EEO reporting scores ranged from $82.52 \%$ from Royal Melbourne Institute of Technology (RMIT) to a low of 0.97\% for Curtin University of Technology. These variances may be explained by two categorical factors: jurisdiction and reputation.

HR Advance (2008) observes that most entities are subject to both federal and State EEO legislation. However, each jurisdiction has a separately administered tribunal and court system overseeing these laws. Federal and State EEO laws provide that it is unlawful to discriminate against a person on certain prohibited grounds of discrimination. Discrimination is unlawful in the area of employment, which includes recruitment during employment and termination of employment. Moreover, in Australia, employers with 100 or more employees are subject to extra legal requirements in relation to promoting and reporting on their practices that support equal opportunity for women in the workplace. They also note that grounds for unlawful discrimination vary between States and Territories (http://www.hradvance.com.au/EEOSummary.asp, accessed 4 April 2008).

As the core EEO legislation is state-based, analysis is conducted to examine possible state effects between universities in New South Wales, Victoria, Queensland, South Australia, Western Australia and other states and territories (due to small sample size issues Tasmanian, Northern Territories and Australian Capital Territories' universities are grouped together).

In addition, there are eight of the original 'sandstone' Australian universities which have banded together to form a more elite grouping which they label 'Group of Eight' (see http://www.go8.edu.au/ website for more information). These eight universities are University of Adelaide, The Australian National University, The University of Melbourne, Monash University, The University of New South Wales, The University of Queensland, The University of Sydney and The University of Western Australia. These are the oldest and richest Australian universities with the most heritage. The implicit message of such a grouping is their excellence standing and performance. Therefore, it is worth examining their EEO practices to test for possible differences.

Tables 2 and 3 analyse the aggregate EEODI by jurisdiction and reputation. These tables show the mean EEODI scores vary widely by jurisdiction. The three most populous states (Victoria, New South Wales and Queensland) have statistically significant higher EEO reporting (31-39\%) than the smaller states and territories (7$17 \%)$. 
Table 2: One way ANOVA of Jurisdiction and Total EEO Disclosure

\begin{tabular}{|c|c|c|c|c|c|c|}
\hline & $\mathbf{N}$ & Mean \% & Std. Dev \% & Std. Error \% & Minimum \% & Maximum \% \\
\hline \multicolumn{7}{|c|}{ Bigger States: EEO Average $35.47 \%$} \\
\hline VIC & 10 & 39.22 & 29.52 & 9.33 & 6.80 & 83.50 \\
\hline NSW & 9 & 35.17 & 22.03 & 7.34 & 3.88 & 71.84 \\
\hline QLD & 9 & 31.61 & 19.14 & 6.38 & 4.85 & 60.19 \\
\hline \multicolumn{7}{|c|}{ Smaller States and Territories: EEO Average $12.14 \%$} \\
\hline WA & 4 & 17.23 & 14.88 & 7.44 & 0.97 & 36.89 \\
\hline SA & 3 & 10.36 & 8.26 & 4.77 & 1.94 & 18.45 \\
\hline Other & 3 & 7.12 & 7.35 & 4.24 & 1.94 & 15.53 \\
\hline Total & 38 & 29.33 & 23.27 & 3.78 & 0.97 & 83.50 \\
\hline
\end{tabular}

Additional analysis of jurisdiction by sub-categories highlights that Western Australian and Queensland universities had the lowest and highest disclosure of 'Race' respectively; New South Wales universities had the highest coverage of 'Religion; Victorian universities had the highest 'Sexual Orientation' and 'Disability' reporting; South Australian universities were lowest in the other four categories.

Table 3: T-test of University 'Prestige' and Total Disclosure

\begin{tabular}{|l|l|c|c|c|c|}
\hline & \multicolumn{1}{|c|}{ 'Prestige' } & N & Mean & Std. Deviation & Std. Error Mean \\
\hline Total disclosure \% & Group of 8 & 8 & 21.97 & 18.74 & 6.63 \\
\cline { 2 - 6 } & $\begin{array}{l}\text { All other Australian } \\
\text { Universities }\end{array}$ & 30 & 31.29 & 24.24 & 4.42 \\
\hline
\end{tabular}

Legend: T-test of 'Prestige' and total EEO disclosure was not significant with a $\mathrm{p}$ value of 0.261 . All similar sub-category analysis (not included due to excessive page length) also showed no statistical difference.

Table 3 data notes no significant differences between the 'Group of Eight' and all other Australian tertiary institutions. However, consistent with the finding of Tower, Plummer, Ridgewell, Goforth and Tower (2008) study of intellectual capital reporting, the Group of Eight universities were less transparent.

There are several other key variables that may predict EEO activity/disclosure patterns. These are size of institution (usually measured as total assets or log of total assets), borrowing levels (measured as total liabilities divided by total assets), profit levels (measured as return on assets which is calculated as net profit divided by total assets). These institutional characteristics (full set of figures not shown for brevity) reveal that:

- $\quad$ The average mean and median size of Australian universities is 1 billion and 800 million Australian dollars respectively,

- $\quad$ Borrowing levels are relatively low at a mean average of 23 percent, and

- $\quad$ Profit levels are moderate averaging $3.8 \%$ as one would expect with a group of public sector institutions.

To better understand these variables as possible predictors a set of ordinary least squared multiple regression was run (not shown to for space reasons). Consistent with the univariate analyses shown in Tables 2 and 3 , the state jurisdiction is a significant statistical predictor (especially when placed into the bigger and smaller state categories) whereas all other variables such as 'Group of Eight' prestige, size, borrowings or profit are not predictors. Multiple regressions run on each of the sub-categories reveal similar results. The one notable exception was the 'Religon' set of EEO items where it was found that bigger and more profitable tertiary institutions, a well as those from the larger states had statistically higher levels of EEO reporting. 


\section{SECTION 3 SUMMARY IMPLICATIONS}

Tertiary institutions would normally be assumed to be paragons of equity and diversity policies and actual procedures. They are public sector bodies whose main function is to provide services to their students, the community and society. However, the results of this study show an overall low level of less than thirty percent of Equal Employment and Opportunity activities reported as measured by the EEO disclosure index.

The findings further revealed substantial differences in these categories with very little information on sexual orientation issues with many of the other major categories reported only in the 30-40\% range. Statistical analysis notes no entity characteristic as causal factors. Richer, older and more prestigious universities are not more transparent. The only significant predictor was the jurisdiction of the entity with universities in the three largest states having far higher information in their annual reports.

Lack of transparency is thus a major concern with low levels of reporting for all key EEO categories. The tertiary education sector may well need to voluntarily put more emphasis on such key issues before pressure to generate legislated mandates mount as the Australian society grows more sensitivity to these key EEO issues.

\section{ACKNOWLEDGEMENTS}

The authors would like to thank Corina Joseph and Norhani Aripin for their valuable assistance in this project.

\section{REFERENCES}

1. Abeysekera, I. 2008. Motivations Behind Human Capital disclosure in Annual Reports Accounting Forum 32: 16-29.

2. Abeysekera, I. and J. Guthrie. 2004. Human Capital Reporting in a Developing Nation. The British Accounting Review 36: 251-268.

3. Adams, C. A., A. Coutts and G. Harte. 1995. Corporate equal opportunities (non-) disclosure. British Accounting Review 27: 87-108.

4. Adams, C. A. and G. Harte. 2000. Making discrimination visible: the potential for social accounting. Accounting Forum 20 (1): 56-79.

5. Adams, C. A. and K. Mcphail, J. 2004. Reporting and the Politics of Difference: (Non) Disclosure on Ethnic Minorities. ABACUS 40 (3): 405-435.

6. http://andrewnorton.info/blog/2008/02/06/is-education-really-australias-biggest-services-export/, accessed 3 April, 2008

7. Brown, A. M., G. Tower and R. Taplin. 2005. Human resource disclosures in the annual reports of Pacific Island countries' entities. Asia Pacific Journal of Human Resources 43 (2): 252-272.

8. Day, R. and T. Woodward. 2004. Disclosure of information about employees in the Directors' report of UK published financial statements: substantive or symbolic? Accounting Forum 28: 43-59.

9. Duff, A. and J. Ferguson. 2007. Disability and accounting firms: Evidence from the UK. Critical Perspectives on Accounting 18: 139-157.

10. Grosser, K. and J. Moon. 2006. Best Practice reporting on Gender Equality in the UK: Data, Drivers and Reporting Choices. In IICCSR Research Paper Series Research paper. Nottingham. University of Nottingham.

11. Group of Eight Universities, accessed on the $21^{\text {st }}$ of March 2008 from http://www.go8.edu.au/

12. HR Advance, accessed on the 4 April 2008 from http://www.hradvance.com.au/EEOSummary.asp.

13. Tower, G., Plummer, J., Ridgewell, B., Goforth, E. and Tower, S. (2008). Intellectual Capital Capabilities of Australian Universities in Relation to Science, Humanities, and Technology, The College Teaching \& Learning (TLC) Conference,Salzburg, Austria, June 23-26.

14. Vuontisjarvi, T. 2006. Corporate social reporting in the European context and human resource disclosures: An analysis of Finnish companies. Journal of Business Ethics 69: 331-354. 